\title{
ANÁLISE DO PERIGO DE INCÊNDIOS FLORESTAIS EM UM MUNICÍPIO DA AMAZÔNIA MATO-GROSSENSE, BRASIL
}

\author{
${ }^{1}$ Luciene Ribeiro; ${ }^{2}$ Ronaldo Viana Soares; ${ }^{2}$ Antonio Carlos Batista, ${ }^{2}$ Ivan Crespo Silva \\ ${ }^{1}$ Bióloga, Dr ${ }^{\mathrm{a}}$, Curitiba, PR. Brasil - lucienefloresta@gmail.com \\ ${ }^{2}$ Eng. Florestal, Dr., Depto. de Ciências Florestais, UFPR, Curitiba, PR, Brasil - rvsoares@ufpr.br; batistaufpr@ufpr.br; ivan@ufpr.br
}

Recebido para publicação: 11/12/2009 - Aceito para publicação: 03/10/2010

\begin{abstract}
Resumo
Com o objetivo de estabelecer o período de maior perigo de incêndios florestais e propor medidas mitigadoras de riscos de incêndios florestais para o município de Novo Mundo, Mato Grosso, Brasil, foi aplicado um estudo de previsão de perigo de incêndios florestais. $\mathrm{O}$ trabalho foi realizado utilizando-se dados de uma série climática correspondente ao período de 2000 a 2005, obtida junto ao Instituto de Meteorologia (INMET). A metodologia aplicada se deu através do cálculo diário do índice de perigo de incêndios florestais, utilizando-se a Fórmula de Monte Alegre (FMA), sendo os dados graficamente representados através do programa A.M.A.D.O. A análise estatística foi realizada com auxílio do programa Statgraphics Centurion XV, e a sazonalidade dos índices de perigo de incêndios foi expressa a partir dos modelos propostos por Box; Jenkins (1976). Foram elaboradas propostas mitigadoras de riscos de incêndios florestais. Os resultados indicaram que os meses de maio, junho, julho e agosto foram os mais perigosos, devido à escassez ou ausência total de precipitação. As medidas mitigadoras de riscos propostas neste estudo são simples e de fácil aplicação, podendo contribuir de forma eficaz e segura para previsão, prevenção e controle de incêndios florestais no município.

Palavras-chave: Fogo; proteção florestal; Amazônia.
\end{abstract}

\begin{abstract}
Fire danger analysis in a county located in Mato Grosso State, Amazon region, Brazil. The aim of this paper were to establish fire season as well as to propose proceedings in order to reduce fire risk, specifically at "Novo Mundo" county, located in "Mato Grosso" State, Brazil. A forest fire forecast methodology was applied to reach the proposed objectives. The research was carried out along 20002005. Fire danger was daily calculated using Monte Alegre Formula, and the results were graphically represented through the A.M.A.D.O. software. The statistics had been developed using Statgraphics Centurion XV program, and applying the methodology proposed by Box and Jenkins (1976). Furthermore, some actions to reduce fire risk had been suggested. Results points to May, June, July and August as the most critical months regarding fire risk, mainly due to the rain shortage along the period. The mitigation measures proposed in this work are easy to implement and could be carried out by county authorities and local community, leading to improvement of forest fire control in the county or even the whole region.

Keywords: Forest fire; forest protection; Amazon.
\end{abstract}

\section{INTRODUÇÃO}

Entre as regiões amazônicas, a porção sul, que contém as florestas do norte do estado de Mato Grosso, é uma das mais críticas no que se refere a desmatamento e incêndios florestais. As condições climáticas, com longo período de estiagem, somadas às formas de manejo da terra submetem essa região a uma transformação florestal intensa, comprometendo a biodiversidade local.

Cochrane; Schulze (1999) verificaram que, em florestas que estão queimando com frequência ou em incêndios de maior intensidade, as árvores grandes parecem ser atingidas da mesma forma que aquelas com diâmetros menores, resultando em taxas de mortalidade semelhantes, mesmo depois de algum tempo após a passagem do fogo. Dessa forma, a vegetação se torna mais suscetível a uma nova 
entrada do fogo e pode causar a extinção local das espécies, conforme já verificado por Melick; Ashton (1991), Nepstad; Moreira; Alencar (1999) e Gerwinga (2000).

Um estudo conduzido por Senna; Costa; Pires (2009), considerando vários graus de desmatamento, mostrou que, em um cenário crítico de recuperação, as florestas do norte do Mato Grosso já não mais poderiam se restabelecer, estando em vias de transformação de floresta tropical em floresta escleromorfa, devido ao desmatamento seguido de queimadas, à pobreza nutricional dos solos e à estiagem prolongada.

Nesse cenário crítico, em que a perda florestal no norte do estado de Mato Grosso parece ser iminente, ações que proponham medidas aplicáveis para previsão, prevenção e controle de incêndios florestais nos municípios da região são relevantes no contexto da conservação da floresta amazônica.

Conforme Soares (1972), os índices de perigo de incêndio são indicadores que refletem antecipadamente a probabilidade de ocorrer um incêndio, assim como a facilidade de sua propagação, com base nas condições atmosféricas do dia ou de uma sequência de dias. Soares (1987) ressalta que a aplicação desses índices é indispensável para os trabalhos de prevenção, sendo que, quando bem ajustados, apresentam elevada correlação com a ocorrência de incêndios.

Para maior eficiência da prevenção dos incêndios florestais, planos regionais ou locais, especificando as técnicas mais adequadas e viáveis, devem ser estabelecidos, pois eles organizam o trabalho de proteção contra incêndios em uma área florestal e podem ser aperfeiçoados de acordo com as necessidades locais.

Partindo da hipótese de que é mais fácil administrar os recursos naturais de forma localizada, os municípios têm capacidade e autonomia para gerir os recursos ambientais presentes em seu território, bastando para isso ter acesso a ferramentas adequadas e de fácil manipulação. Nesse sentido, o presente trabalho teve como objetivo determinar e descrever o comportamento do índice de perigo de incêndios no período de 2000 a 2005 e elaborar propostas de mitigação de riscos de incêndios florestais no âmbito do poder público estadual e municipal e da comunidade.

\section{MATERIAL E MÉTODOS}

\section{Área de estudos}

O município de Novo Mundo está localizado entre as coordenadas geodésicas $09^{\circ} 09^{\prime 2} 29^{\prime \prime} \mathrm{S}$, 49 $58^{\prime} 59^{\prime \prime}$ W e $10^{\circ} 29^{\prime} 28^{\prime \prime} \mathrm{S}$ e $48^{\circ} 55^{\prime} 52^{\prime \prime} \mathrm{W}$, com uma área de $5.794,7 \mathrm{~km}^{2}$. A altitude média da sede do município é de $330 \mathrm{~m}$. O clima da região, segundo a classificação de Köppen, é do tipo Aw, equatorial quente e úmido, com dois a quatro meses de seca. No período analisado, a precipitação anual foi cerca de $2000 \mathrm{~mm}$ e a temperatura média em torno de $25^{\circ} \mathrm{C}$.

\section{Cálculo do Índice de Perigo de Incêndios}

Obtenção de dados meteorológicos

As informações meteorológicas constituem as bases para os cálculos da Fórmula de Monte Alegre (FMA), o Índice de Perigo de Incêndios (IPI) utilizado. As informações climáticas foram oriundas da Estação Meteorológica Convencional de Matupá, distante $45 \mathrm{~km}$ do município de Novo Mundo, localizada nas coordenadas geodésicas $10^{\circ} 15^{\prime} \mathrm{S}$ e $54^{\circ} 55^{\prime} \mathrm{W}$, com altitude de 285 metros.

A série climática utilizada foi referente aos anos de 2000 a 2005 , sendo os dados obtidos junto ao Instituto Nacional de Meteorologia (INMET). Em determinadas datas não houve registro dos valores diários das variáveis, fato decorrente da ausência de funcionários ou de danos nos equipamentos. Para que não houvesse lacunas, as variáveis temperatura e umidade relativa do ar naquelas datas foram obtidas através de valores médios referentes ao mesmo dia e mesmo mês dos anos que compuseram a série analisada. Para as lacunas referentes à precipitação foi utilizado o valor zero.

Os dados climáticos de temperatura e precipitação foram representados de forma gráfica, de acordo com o diagrama climático (climograma) sugerido por Walter; Lieth (1967), baseados na metodologia de Gaussen (1954), que considera que um mês é seco quando o quociente da média dos totais mensais das precipitações pluviométricas $(\mathrm{mm})$ é inferior a $2{ }^{\circ} \mathrm{C}$ de temperatura média mensal. A vantagem desse tipo de representação é a melhor visualização do período seco e do chuvoso.

\section{Aplicação da fórmula para obtenção do índice de perigo de incêndio}

Foi adotada a FMA para a obtenção do Índice de Perigo de Incêndios (IPI). Essa fórmula, desenvolvida através de dados da região central do estado do Paraná por Soares (1972), foi escolhida para 
ser utilizada no presente trabalho por ser simples e utilizar variáveis meteorológicas de fácil obtenção (precipitação e umidade relativa do ar). É representada pela seguinte equação:

\section{$F M A=\sum_{i=1}^{n}\left(100 / H_{i}\right)$}

Em que: FMA = Fórmula de Monte Alegre;

$\mathrm{H}=$ Umidade relativa do ar $(\%)$, medida às 13 horas;

$\mathrm{n}=$ Número de dias sem chuva.

A tabela 1 indica as restrições à somatória do índice FMA de acordo com a precipitação do dia (SOARES, 1972).

Tabela 1. Ajustes de cálculo de acordo com a precipitação.

Table 1. Precipitation restrictions to the fire index summation.

\begin{tabular}{ll}
\hline Chuva do dia $(\mathbf{m m})$ & Modificação do cálculo \\
\hline$\leq 2,4$ & Nenhuma \\
2,5 a 4,9 & Abater $50 \%$ na FMA calculada na véspera e somar $(100 / \mathrm{H})$ do dia. \\
5,0 a 9,9 & Abater $60 \%$ na FMA calculada na véspera e somar $(100 / \mathrm{H})$ do dia. \\
10,0 a 12,9 & Abater $80 \%$ na FMA calculada na véspera e somar $(100 / \mathrm{H})$ do dia. \\
$>12,9$ & Interromper o cálculo $(\mathrm{FMA}=0)$ e recomeçar somatória no dia seguinte. \\
\hline
\end{tabular}

A escala do grau de perigo da FMA, conforme Soares (1972) está descrita na tabela 2. Quanto menor o valor da FMA, menor será o IPI.

Tabela 2. Escala do grau de perigo da FMA.

Table 2. Fire danger index degrees.

\begin{tabular}{ll}
\hline Valor de FMA & Grau de perigo \\
\hline$\leq 1,0$ & Nulo \\
1,1 a 3,0 & Pequeno \\
3,1 a 8,0 & Médio \\
8,1 a 20,0 & Alto \\
$\geq 20,0$ & Muito alto \\
\hline
\end{tabular}

Representação gráfica do Índice de Perigo de Incêndios (IPI)

Para a correta representação gráfica dos dados do IPI, foi utilizado o Programa A.M.A.D.O (BERTIN, 1986). Este programa é o que melhor expressou os dados, pois sendo os cálculos diários, eles não podem ser representados pela média de valores e sim individualmente para cada dia de cada mês de cada um dos anos estudados.

\section{Análise estatística do Índice de Perigo de Incêndios (IPI)}

A estatística aplicada foi a Análise de Séries Temporais, que se caracteriza como um conjunto de observações tomadas em tempos determinados, comumente em intervalos iguais, e consiste em uma descrição matemática dos movimentos dos componentes básicos que se apresentam. Tal análise possibilita uma investigação do comportamento dos dados ao longo de um período determinado de tempo (SPIEGEL, 1977).

Dos modelos que compõem a Análise de Séries Temporais, foram adotados no presente trabalho os propostos por Box; Jenkins (1976), também conhecidos como ARIMA, que consistem em modelos lineares que associam de forma conjunta uma parte autorregressiva e uma parte das médias móveis, ou seja, é feita a integração dos processos (modelos autorregressivos e médias móveis). O modelo pode ser designado por ARIMA $(p, d, q)$, em que $p$ e $q$ são, respectivamente, a quantidade de parâmetros autorregressivos (AR) e médias móveis (MA) e $d$ o número de diferenças necessárias para transformar a série em estacionária. 
O modelo ARIMA foi ajustado para o Modelo Autorregressivo Integrado Médias Móveis Sazonal SARIMA (p,d,q)X(P,D,Q), com o objetivo de melhorar o modelo a ser ajustado para esta série temporal. As informações foram processadas no programa Statgraphics Centurion XV 2005, o qual gerou um gráfico que evidenciou a sazonalidade dos dados, bem com a tendência de elevação do IPI durante os três últimos anos da série analisada.

\section{RESULTADOS E DISCUSSÃO}

\section{Análise dos fatores climáticos}

Os episódios climáticos "El Niño" e "La Niña" têm diferentes graus de influência sobre as regiões, podendo afetá-las de forma fraca, moderada ou intensa, de acordo com observações regulares no comportamento climático, registradas pelo Instituto Nacional de Pesquisas Espaciais (INPE), que descreve seu grau de influência. Dentre as alterações climáticas causadas por esses episódios, a mudança na intensidade, distribuição e frequência da precipitação é o fator que mais influencia a probabilidade de risco de incêndio florestal.

Conhecer o comportamento climático das principais variáveis de uma dada região contribui para o planejamento da prevenção de incêndios florestais. O cruzamento das variáveis de temperatura e precipitação evidencia o período de chuva e estiagem, conforme diagrama climático (Figura 1), sugerido por Walter-Lieth (1967).

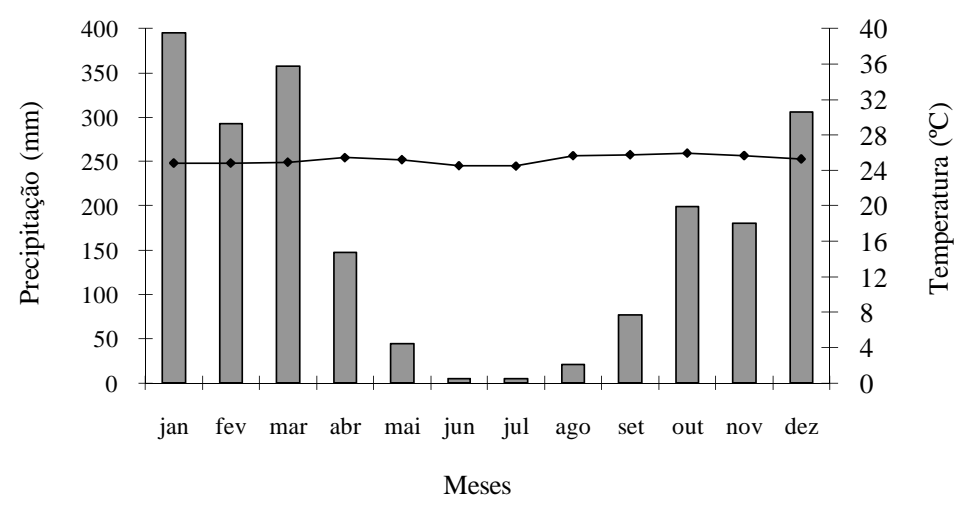

Figura 1. Diagrama climático de Walter-Lieth para o período de 2000-2005.

Figure 1. Walter-Lieth's climate diagram in the period 2000-2005.

A temperatura média foi de $25{ }^{\circ} \mathrm{C}$, apresentando uma oscilação em torno de $2,5^{\circ} \mathrm{C}$ ao longo do período analisado. A temperatura máxima foi de $26,5^{\circ} \mathrm{C}$ nos meses mais quentes e de $24{ }^{\circ} \mathrm{C}$ nos meses mais frios (junho e julho), tornando a linha que expressa essa variável quase como constante ou reta. Isso significa que não há um período de temperatura baixa nos meses que correspondem ao verão e inverno, pois essas estações, nessa região, são caracterizadas por período chuvoso e não chuvoso, respectivamente, e não pela elevação ou queda acentuada da temperatura.

No período de estiagem ocorre diminuição dos valores de umidade relativa do ar, aumentando os riscos de incêndios florestais, pois valores inferiores a $50 \%$ produzem riscos iminentes de fogo. De acordo com Soares; Batista (2002), incêndios florestais que ocorrem com valores de umidade relativa do ar abaixo de 30\% são muito difíceis de combater, pois podem adquirir grandes intensidades.

Para o município estudado, o diagrama indicou os meses de maio, junho, julho e agosto como os mais secos. Conforme os dados analisados, foi verificado que o período de seca tem início na primeira quinzena de maio e termina no fim de agosto. Em setembro reinicia a estação chuvosa. Entretanto, em determinados anos podem ocorrer até três meses (junho, julho e agosto) seguidos sem que haja pluviosidade, como aconteceu no ano de 2005. 
A média da precipitação total anual para o período analisado foi em torno de $2.000 \mathrm{~mm}$, com intensidade máxima em dezembro, janeiro, fevereiro e março. $\mathrm{O}$ ano de 2004 foi o que apresentou maior precipitação, com 2.202,7 mm, e o menor valor foi registrado em 2002, com 1.631,5 mm.

\section{Comportamento do Índice de Perigo de Incêndio (IPI) nos anos de 2000 a 2005}

Comportamento do IPI durante o ano de 2000

De acordo com o INPE, o ano de 2000 (Figura 2) esteve sob influência moderada do episódio climático "La Niña". Nesse ano, nos meses de maio e julho não houve nenhuma precipitação. O único registro de pluviosidade para o período de estiagem ocorreu em 27 de junho, com precipitação de $25,2 \mathrm{~mm}$. O índice permaneceu com um grau de perigo muito alto durante 104 dias, com um valor máximo de 151 em 29 de agosto.

A média mensal da umidade relativa para o período seco ficou abaixo de $50 \%$ e assim permaneceu por 83 dias, registrando o valor mínimo em 4 de julho, com apenas $25 \%$. Foram 120 dias sem precipitação, sendo que a primeira ocorreu em 30 de agosto, com um total de $66 \mathrm{~mm}$, e encerrou o período de estiagem do ano de 2000.

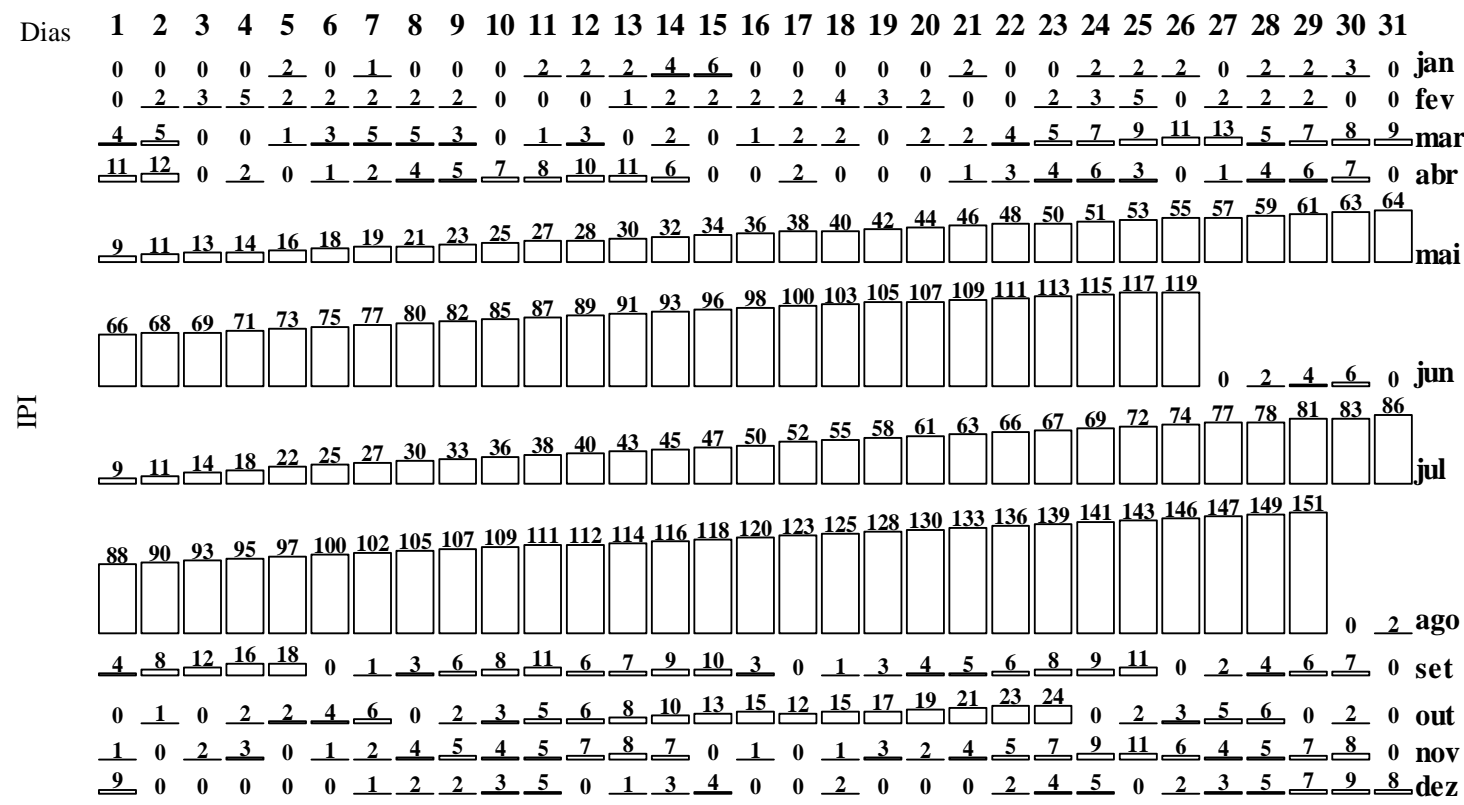

Figura 2. Comportamento do índice de perigo de incêndios (IPI) durante o ano de 2000.

Figure 2. Fire danger index behavior in the year 2000.

Comportamento do IPI durante o ano de 2001

O ano de 2001 (Figura 3) esteve também sob influência de efeito moderado do episódio "La Niña", e durante 80 dias ininterruptos (11 de junho a 30 de agosto) prevaleceu o grau de perigo muito alto. O maior valor ocorreu em 30 de agosto, com um índice de 210. Foram 101 dias sem chuva, sendo os meses de junho e julho os mais secos. Nesse ano, o grau de perigo alcançou valores maiores do que em 2000 e 2002.

A média mensal da umidade relativa para o período seco ficou abaixo de $50 \%$ e permaneceu por 60 dias interruptos. O valor mínimo registrado foi de 29\%, em 18 de agosto. Em 31 de agosto teve início o período chuvoso, com uma precipitação de $18 \mathrm{~mm}$, encerrando assim o perigo de incêndios florestais para o ano de 2001. 


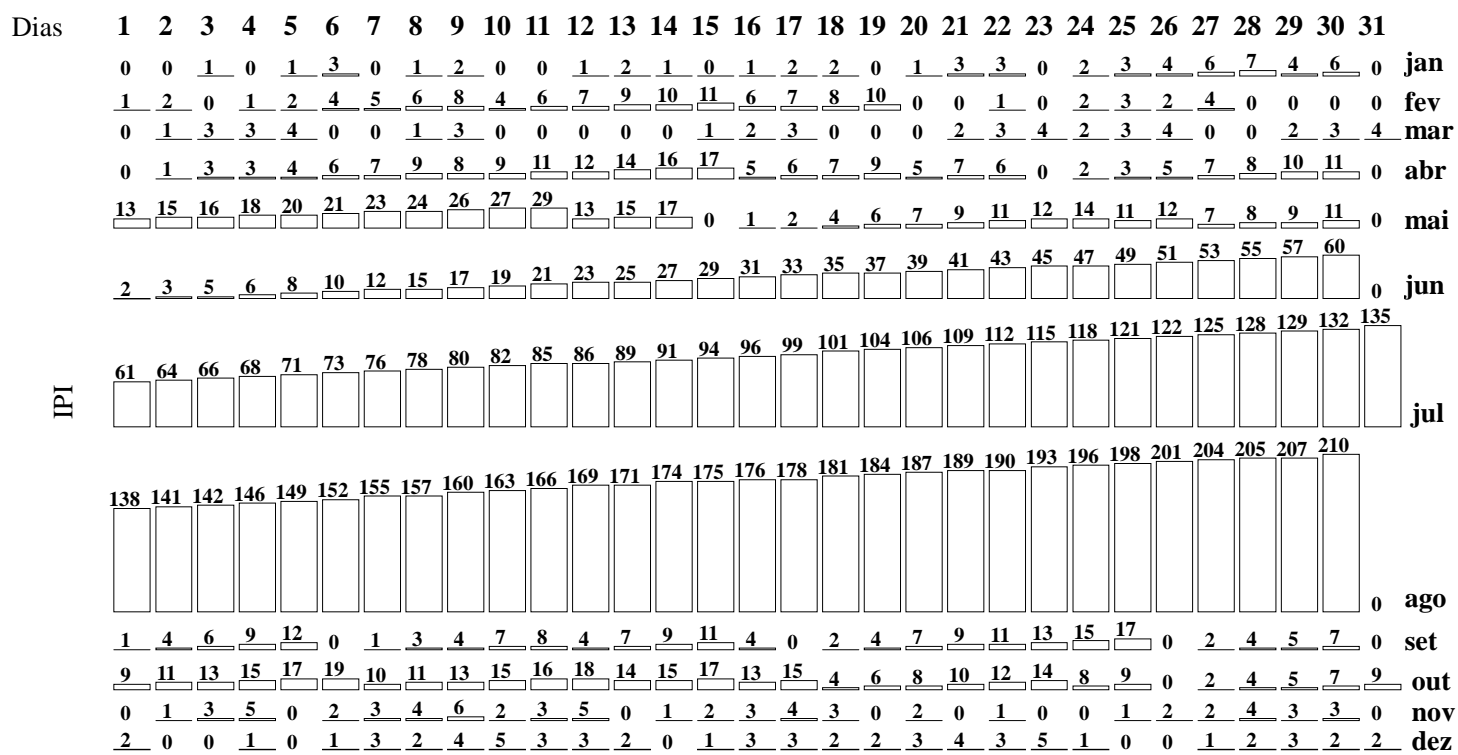

Figura 3. Comportamento do índice de perigo de incêndios (IPI) durante o ano de 2001.

Figure 3. Fire danger index behavior in the year 2001.

Comportamento do IPI durante o ano de 2002

O ano de 2002 (Figura 4) esteve sob moderada influência do episódio "El Niño", registrando menor precipitação $(1.631,5 \mathrm{~mm})$ do que nos outros anos. O período de estiagem apresentou 122 dias sem precipitação.

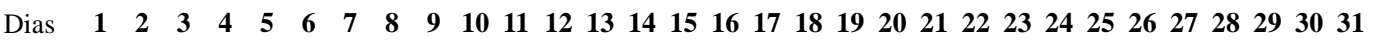

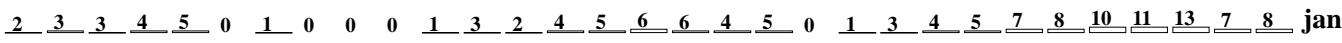
$\begin{array}{lllllllllllllllllllllllllllllllll}9 & 11 & 0 & 0 & 0 & 2 & 2 & 0 & 1 & 0 & 0 & 0 & 0 & 1 & 2 & 0 & 1 & 3 & 2 & 3 & 5 & 2 & 3 & 4 & 2 & 3 & 4 & 3 & 0 & 0 & 0 & f e v\end{array}$

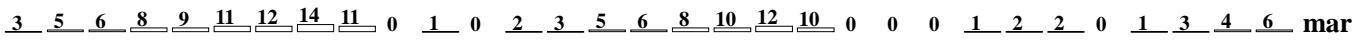

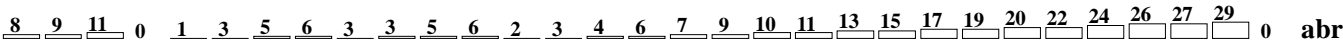

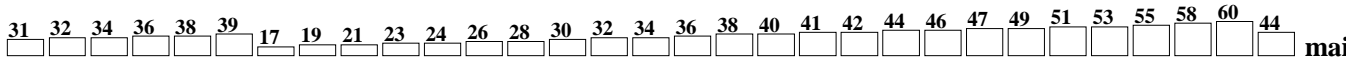
$\begin{array}{llllllllllllllllllllllllllllllllll}46 & 48 & 50 & 52 & 54 & 56 & 58 & 61 & 64 & 66 & 68 & 70 & 73 & 75 & 76 & 78 & 81 & 83 & 85 & 87 & 89 & 91 & 92 & 94 & 96 & 98 & 100 & 101 & 103 & 105\end{array}$

$\overline{\underline{\theta}}$

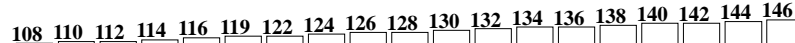

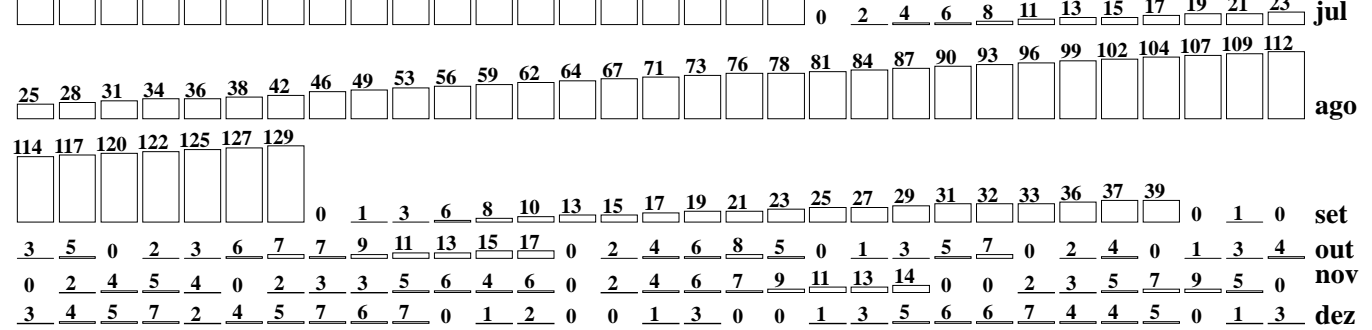

Figura 4. Comportamento do índice de perigo de incêndios (IPI) durante o ano de 2002.

Figure 4. Fire danger index behavior in the year 2002.

Os valores do índice foram menores do que os registrados para todos os anos analisados, sendo o maior valor alcançado em 19 de julho, com índice de 146. Foram 96 dias com grau de perigo muito alto. 
A média mensal da umidade relativa para o período seco ficou abaixo de $50 \%$ por 81 dias ininterruptos. O menor valor registrado foi em 08 de agosto, com $25 \%$. Em 08 de setembro, uma precipitação de $19 \mathrm{~mm}$ anulou o índice de perigo, iniciando o período chuvoso.

Comportamento do IPI durante o ano de 2003

O ano de 2003 (Figura 5) também esteve sob influência moderada do episódio "El Niño". No primeiro dia de junho houve apenas uma precipitação de $10 \mathrm{~mm}$, e nos meses de julho e agosto não houve precipitação. Foram 109 dias sem precipitação, o que contribuiu para que o índice apresentasse elevação contínua, permanecendo com grau de perigo muito alto durante 105 dias. O valor mais elevado foi registrado em 01 de setembro (234) e permaneceu muito alto até 19 de setembro.

A média mensal da umidade relativa para o período seco ficou abaixo de $50 \%$ e permaneceu por 60 dias interruptos. O menor valor foi registrado em 22 de julho (25\%). Em 20 de setembro iniciou o período chuvoso, com uma precipitação de $18,2 \mathrm{~mm}$, encerrando assim o período de perigo de incêndios do ano de 2003.

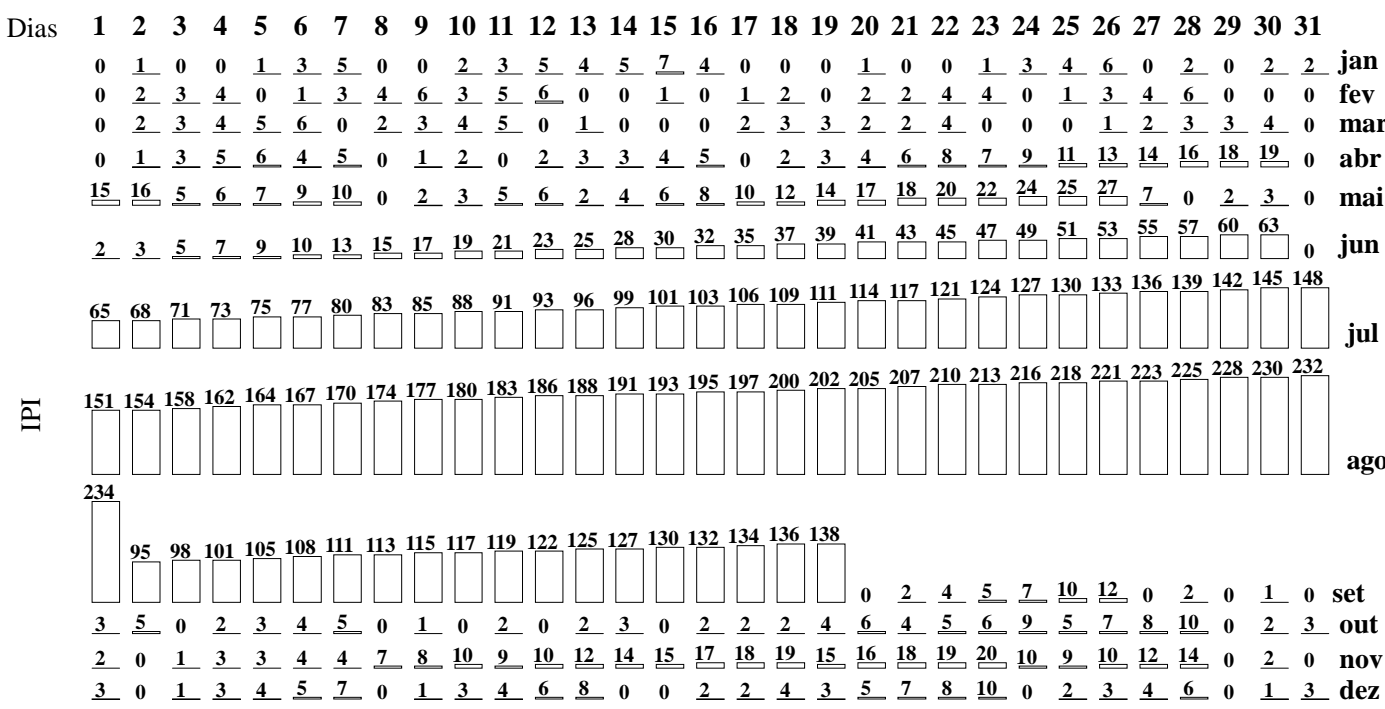

Figura 5. Comportamento do índice de perigo de incêndios (IPI) durante o ano de 2003.

Figure 5. Fire danger index behavior in the year 2003.

Comportamento do IPI durante o ano de 2004

$\mathrm{O}$ ano de 2004 (Figura 6) esteve sob fraca influência do "El Nino". Foi o ano com maior precipitação da série analisada, com um valor total de $2.202,7 \mathrm{~mm}$. O mês de junho não apresentou precipitação, e em julho a precipitação foi de apenas 1,1 $\mathrm{mm}$. O índice permaneceu muito alto durante os meses de junho, julho, agosto e até o dia 22 de setembro, registrando o valor mais alto (276) em 31 de agosto. O grau de perigo muito alto permaneceu até 22 de setembro. Nesse ano, foram 116 dias sem precipitação e 119 dias com grau de perigo muito alto.

A média mensal da umidade relativa para o período seco ficou abaixo de $50 \%$ e permaneceu por 105 dias, sendo o valor mais baixo registrado em 09 de setembro, com valor de $21 \%$. As chuvas tiveram início somente no dia 23 de setembro, quando houve uma precipitação de $20,8 \mathrm{~mm}$, dando início ao período chuvoso.

Comportamento do IPI durante o ano de 2005

O ano de 2005 (Figura 7) esteve também sob influência fraca do episódio "El Niño". O município apresentou uma precipitação total média de 2.182,9 $\mathrm{mm}$ e apresentou 3 meses (junho, julho e agosto) seguidos de ausência de precipitação. A precipitação cessou em 29 de maio e foram contabilizados 117 dias sem chuva, fato que contribuiu para a ocorrência de 115 dias de grau de perigo muito alto, com um valor máximo de 294, registrado em 31 de agosto. 
Nesse ano, o índice alcançou valores maiores do que nos outros anos da série analisada. A estiagem contribuiu para que o município fosse submetido a 119 dias com valores de umidade relativa do ar menor que 50\%, sendo o valor mais baixo de 19\%, registrado em 29 de julho. A chuva retornou somente em 27 de setembro, com 15,2, mm encerrando o período de seca de 2005.

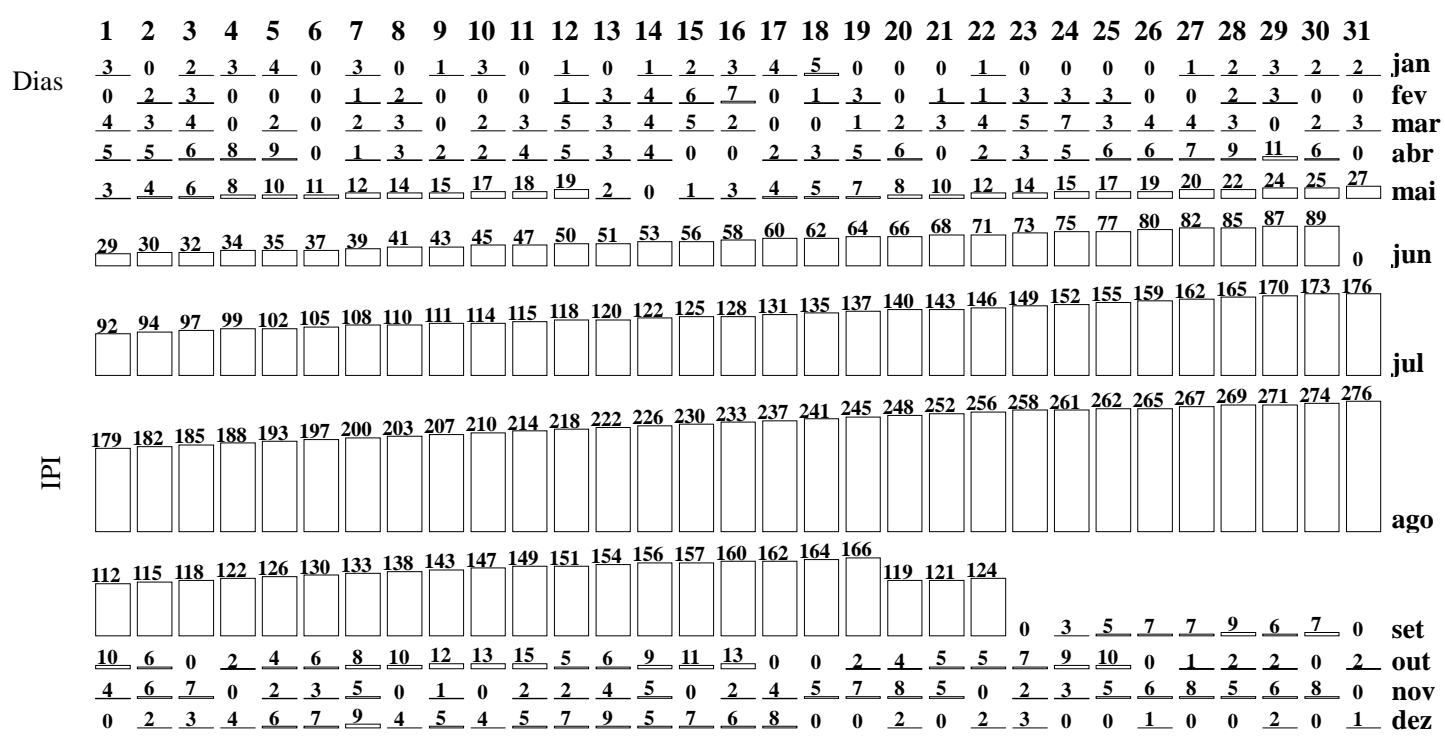

Figura 6. Comportamento do índice de perigo de incêndios (IPI) durante o ano de 2004.

Figure 6. Fire danger index behavior in the year 2004.

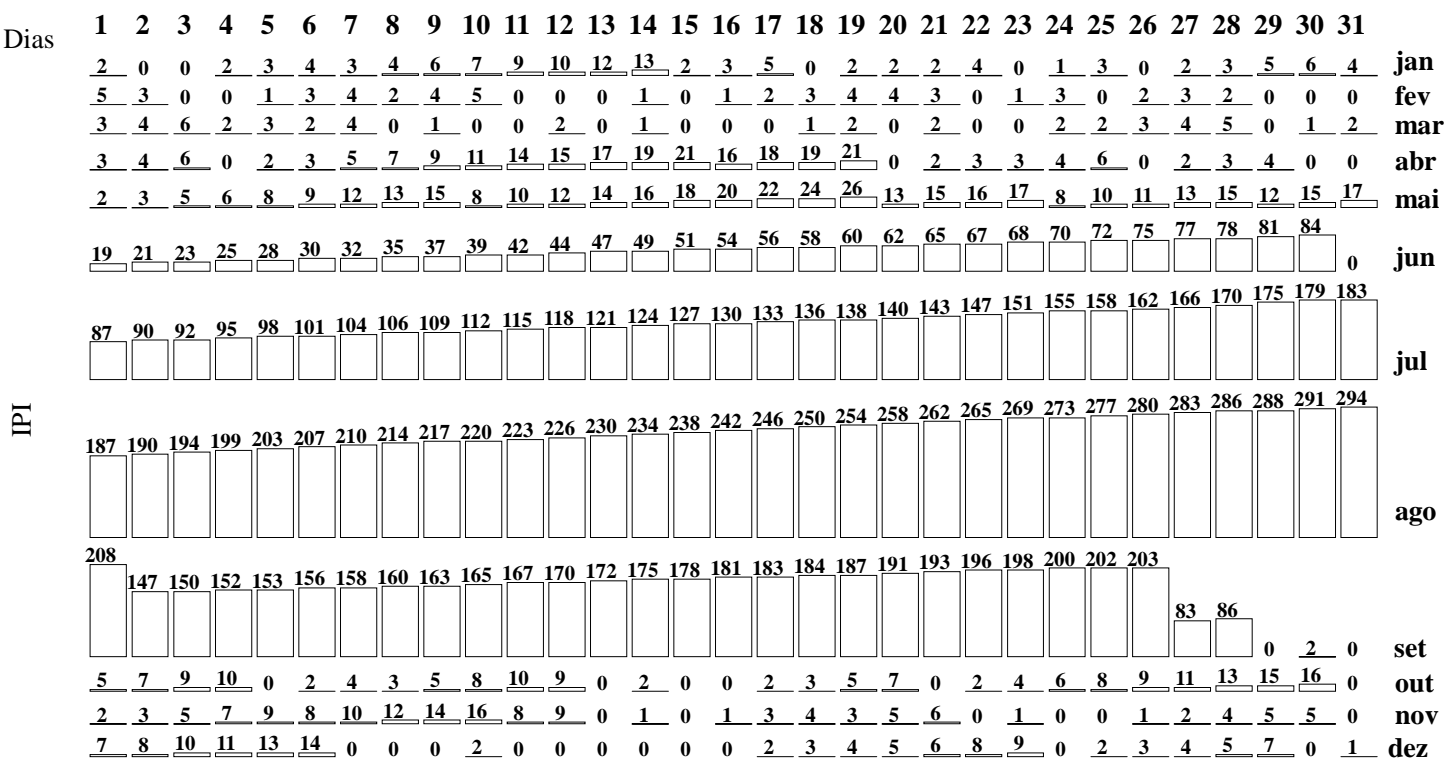

Figura 7. Comportamento do índice de perigo de incêndios (IPI) durante o ano de 2005.

Figure 7. Fire danger index behavior in the year 2005.

Considerações gerais sobre o índice de perigo de incêndio (IPI)

A partir da avaliação dos valores mensais mínimos e máximos do IPI, foi possível observar o seu comportamento durante os diferentes períodos do ano, com os seguintes graus de perigo: 
Janeiro: 0 - 2,07 (nulo a pequeno);

Fevereiro: 0 - 2,40 (nulo a pequeno);

Março: 0 - 2,80 (nulo a pequeno);

Abril: 4,0 - 12,0 (médio);

Maio: 12,0 - 27,0 (alto a muito alto);

Junho: 27,1 - 70,0 (muito alto);

Julho: 70,1 - 108,0 (muito alto);

Agosto: 108,1 - 293,5 (muito alto);

Setembro: 0 - 233,8 (inicia-se com perigo muito alto e declina até nulo);

Outubro: 0 - 6,29 (nulo a médio);

Novembro: 0 - 5,28 (nulo a médio);

Dezembro: 0 - 3,06 (nulo a pequeno).

O comportamento do IPI com base na série temporal analisada possibilitou a definição de um calendário de níveis de alerta para o poder público estadual e municipal em conjunto com a comunidade, para a aplicação de medidas de prevenção e controle de incêndios florestais. A elaboração desse calendário contribui para a alocação de recursos no período certo do ano, evitando-se investimentos desnecessários.

O nível de alerta recomendado para cada grau de perigo e de acordo com os meses do ano está descrito na tabela 3 .

Tabela 3. Período (meses), graus de perigo e níveis de alerta quanto aos riscos de incêndios florestais.

Table 3. Period (months), danger degrees, and alert level for forest fire risk.

\begin{tabular}{lcc}
\hline Meses & Grau de perigo & Níveis de alerta \\
\hline Dezembro a março & Nulo a pequeno & Sem necessidade \\
Abril & Médio & Moderado \\
Maio & Alto a muito alto & Máximo \\
Junho a agosto & Muito alto & Máximo \\
Setembro & Muito alto a médio & Máximo - moderado \\
Outubro e novembro & Médio a nulo & Sem necessidade \\
\hline
\end{tabular}

O calendário prevê quatro níveis de alerta quanto aos riscos de incêndios florestais:

- O primeiro abrange um período sem necessidade de alerta, pois é o período chuvoso, que vai dos meses de dezembro a março;

- O segundo se refere ao mês de abril, no qual as chuvas escasseiam, gerando um nível de alerta moderado;

- O terceiro nível exige alerta máximo e abrange os meses de maio a agosto. Compreende o período de estiagem, no qual ocorrem os incêndios;

- O quarto nível se refere ao mês de setembro, em que as chuvas recomeçam, mas podem atrasar. Nesse caso, recomenda-se o nível de alerta máximo até o início do período chuvoso, que pode iniciar na primeira ou segunda quinzena do mês.

\section{Análise estatística}

A análise de série temporal possibilitou fazer inferências sobre as propriedades básicas do mecanismo gerador do processo estocástico observado na série estudada. A abstração de regularidades contidas nos fenômenos observáveis dessa série possibilitou a construção de um modelo matemático como uma representação simplificada da realidade dos fenômenos causais. Para tanto, foi realizado o ajuste do modelo ARIMA, adicionando-se a sazonalidade, sendo este transformado em $\operatorname{SARIMA}(1,0,0) \mathrm{X}(0,0,0)_{12}$ e definindo o modelo como $\operatorname{ARIMA}(1,0,0)$. No ajuste foi aplicada a técnica do Backforecasting. A variância do ruído branco foi ${ }_{\mathrm{a}}{ }_{\mathrm{a}}^{2}=114,355$ com 2.190 G.L (Graus de Liberdade), podendo ser considerado de boa qualidade. O Valor-p correspondente ao teste de nulidade dos parâmetros $\phi_{\mathrm{i}}$ e $\delta$ foram todos menores do que 0,05 , indicando a sua significância estatística.

A expressão do modelo ajustado foi: 


$$
\mathrm{Zt}=\delta+\phi_{\mathrm{iZt}}-1+\text { at }
$$

Em que: $\mathrm{Zt}=$ valor da série temporal no instante $t$;

$\delta=$ representa o termo constante da série;

$\phi_{\mathrm{i}}=$ parâmetros autorregressivos, $i=1,2, \ldots, p$;

at $=$ representa o ruído branco.

Os parâmetros estão descritos na tabela 4 .

Tabela 4. Sumário do modelo ARIMA $(1,0,0)$.

Table 4. ARIMA $(1,0,0)$ model summary.

\begin{tabular}{lcccc}
\hline Parâmetro & Estimativa & Erro padrão & t & P-value \\
\hline AR(1) & 0,976667 & 0,00458245 & 213,132 & 0,000000 \\
Média & 30,7673 & 9,72163 & 3,16483 & 0,001552 \\
Constante & 0,717899 & & & \\
\hline
\end{tabular}

A análise estatística mostrou a sazonalidade do perigo de incêndio (Figura 8), evidenciada no comportamento dos dados, revelando em picos os altos valores obtidos para o índice durante o período analisado. O índice alcançou os valores máximos de 234, 276 e 294 nos anos de 2003, 2004 e 2005, respectivamente, demonstrando uma tendência de elevação.

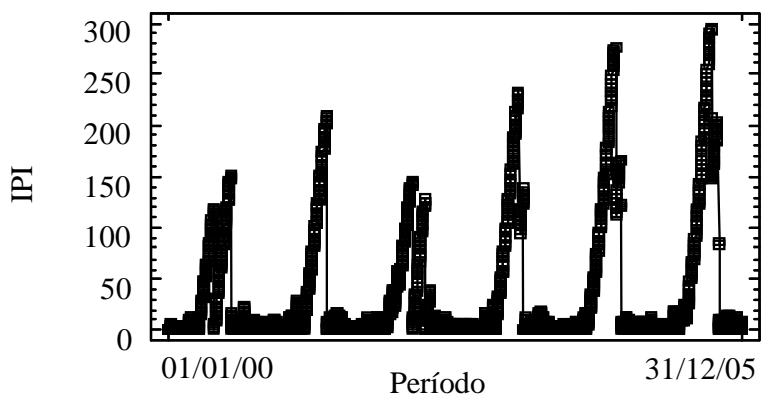

Figura 8. Sazonalidade do perigo de incêndios florestais (IPI) para o período de 2000 a 2005.

Figure 8. Seasonality of forest fire danger in the period 2000-2005.

A sazonalidade (efeitos que tendem a se repetir em determinados períodos de tempo) verificada para o índice de perigo de incêndio está de acordo com o padrão de distribuição da precipitação ao longo dos anos, sendo que em determinado período do ano as chuvas são intensas, mas em outro ela escasseia até a ausência total, por longos dias ou meses.

A sazonalidade do perigo encontra-se também em consonância com o longo período de baixa umidade relativa do ar (abaixo de 50\%) que ocorreu por vários dias consecutivos, durante o período de estiagem. A ausência de pluviosidade e baixa umidade relativa do ar contribuíram para que os valores do índice de perigo de incêndio fossem elevados.

A esses fatores pode ser adicionado também o fator humano, que contribui para a ocorrência de incêndios, através das práticas do uso do fogo sem o devido planejamento. A isso se acrescentam também alguns mecanismos que contribuem para o combate aos incêndios florestais, mas que estão ausentes no município, como exemplo a formação de brigadas e batalhão do corpo de bombeiros.

A corporação do corpo de bombeiros mais próxima de Novo Mundo encontra-se na cidade de Alta Floresta, distante $105 \mathrm{~km}$ e sem estar adaptada adequadamente para o combate aos incêndios florestais. Além disso, as estradas de terra geralmente se encontram em péssimas condições de tráfego, impossibilitando o acesso em tempo hábil para a contenção de um incêndio.

\section{Propostas mitigadoras de riscos de incêndios florestais}

Algumas ações por parte da administração municipal e estadual e até mesmo pela comunidade local podem ser tomadas para prever, prevenir e controlar incêndios florestais. Exemplos: 
Administração municipal:

1- Estruturar um setor dentro de uma secretaria (Meio Ambiente ou Agricultura) para monitorar diariamente os riscos de incêndios florestais no período de estiagem (abril a setembro), com um programa computacional, por exemplo, o "Programa Prometheus" (NUNES, SOARES e BATISTA, 2007), que permite alimentar digitalmente as variáveis meteorológicas para se calcular o índice de perigo de incêndios florestais.

2- Requerer junto ao INMET a instalação de uma estação meteorológica dentro do município, para obtenção de dados confiáveis, pois essas informações são obtidas atualmente em municípios vizinhos.

3- Estabelecer um comprometimento municipal de informar, através da mídia local (rádio, carros de som, panfletos, placas indicativas), o risco de incêndios florestais para o dia, bem como os cuidados a serem tomados pela população.

4- Determinação dos pontos de coleta de água em caso de emergência, tendo por base a localização dos vários rios existentes no município, além da conscientização da população para sua preservação.

5- Utilização de mapas de riscos de incêndios florestais, conforme estudo já realizado por Ribeiro (2009), para delimitar as áreas de maior risco e investir em prevenção de forma localizada, diminuindo custos e tempo nesses investimentos.

6- Elaborar um plano de prevenção e combate de incêndios florestais específico para o município, considerando todas as suas peculiaridades.

Administração estadual:

1- O órgão responsável pela liberação de queimadas em Mato Grosso, atualmente a Secretaria de Defesa Civil, ligada à Secretaria Estadual de Meio Ambiente (SEMA), deveria estipular um prazo maior de proibição de queimadas, iniciando o período proibitivo em junho e não em julho, como ocorre atualmente.

2- Fazer o Registro de Ocorrência de Incêndios (R.O.I.) para que futuramente trabalhos relativos à frequência das ocorrências e sua relação com os índices de perigo possam ser analisados. Atualmente não existe nenhuma informação (segundo informações verbais dos coordenadores da Defesa Civil em julho de 2007) sobre as ocorrências de incêndios no município.

3- Instalar um núcleo bem equipado do corpo de bombeiros no município de Novo Mundo, pois as condições das estradas intermunicipais não permitem o acesso eficiente e em tempo hábil de uma brigada de incêndios florestais ou corpo de bombeiros de outro município. Sendo assim, os incêndios são às vezes contidos pelos próprios habitantes e, na maioria das vezes, não consegue ser debelado.

Administração municipal e estadual:

1- Desenvolver projetos de educação ambiental especificamente voltados para a questão do fogo em escolas públicas municipais e estaduais, enfocando a realidade do município em relação ao uso do fogo como forma de manejo do solo.

2- Realizar anualmente, com participação da Prefeitura, SEMA, IBAMA, INCRA, Universidades (estadual e federal), sociedade organizada e ONG's, campanhas sociais de conscientização, contendo palestras, brincadeiras, jogos, apresentação de filmes, músicas, pinturas, teatro e distribuição de brindes, de forma que envolva toda a população, funcionando como um ato em prol da forma correta da prevenção, uso e controle do fogo.

Comunidade:

1- Considerando que, no município estudado, a maior parte dos incêndios ocorridos no passado teve início às margens das estradas (RIBEIRO; SOARES; BATISTA, 2008) por fumantes ou incendiários, a implantação de cortinas verdes ou de segurança nas margens delas contribuiria para reduzir esses incêndios.

2- O plantio de espécies frutíferas deve ser estimulado tanto no núcleo urbano quanto na agricultura familiar, por ter crescimento rápido e ser fonte de alimento e renda, além de que não necessita de uso do fogo e ainda contribui para a menor dependência de alimentos de outros centros produtores.

3- Outras medidas simples e eficientes podem ser difundidas dentro dos assentamentos: 
a) Capacitação de multiplicadores detentores de conhecimento sobre uso, controle e prevenção do fogo (líderes comunitários, professores, líderes religiosos, comerciantes locais e outros).

b) Alertas para o risco de incêndios florestais, como campanhas educativas que expressem, além dos cuidados, as punições cabíveis em casos de perda de controle da queima; conscientização da população sobre os custos das possíveis perdas do patrimônio natural e material que pode acontecer diante da falta de controle sobre o fogo.

c) Criar e manter um sistema interno de informação dentro dos assentamentos sobre os locais (lotes) onde haverá a queima. Para tanto, devem-se utilizar cartazes expostos nos bares, mercados e igrejas presentes nas comunidades, além da informação verbal entre os habitantes.

d) A queima deve ocorrer sempre com permissão dos órgãos competentes, e os vizinhos devem ser informados, para que estejam de prontidão caso haja perda do controle da queima.

e) Comunicar oficialmente aos órgãos competentes do município a realização de queimas e solicitar equipamentos (tratores e outros) de apoio à construção ou manutenção de aceiros antes da queima.

f) Por medida de segurança, deve-se fazer a queima em apenas um lote, ou grupo de lotes, por dia.

g) Formação de grupos, constituídos dentro dos próprios assentamentos para acompanhamento e apoio no processo de queima e controle do fogo nas propriedades vizinhas.

\section{CONCLUSÕES}

- A análise do comportamento do grau de perigo através da FMA se mostrou eficiente, evidenciando o período do ano em que o grau de perigo foi maior, em consonância com o diagrama climático e pelos resultados estatísticos que comprovaram a sazonalidade do perigo.

- A análise dos graus de perigo de incêndio contribuiu para a elaboração de um calendário de alerta, composto por quatro níveis.

- As proposições elaboradas neste trabalho, se aplicadas pela administração municipal e comunidade, podem contribuir efetivamente para previsão, prevenção e controle de incêndios florestais no município de Novo Mundo, Mato Grosso.

\section{REFERÊNCIAS}

BERTIN, J. A neográfica e o tratamento gráfico da informação. Curitiba: Ed. UFPR, 1986. 273 p.

BOX, G. E. P.; JENKINS, G. M. Times series analysis: forecasting and control. Ed. Holden Day, 1976.

COCHRANE, M. A.; SCHULZE, A. Positive feedbacks in the fire dynamics of closed canopy tropical forests. Science. p. 1832 - 1835, 1999.

GAUSSEN, H. Theories et classification des climats et microclimats. In: CONGRES INTERNATIONALE DE BOTANIQUE, 8. 1954, Paris. Compte-Rendu. Paris, Section 7 et 3, p. 125 130, 1954.

GERWINGA. J. J. Degradation of forests throughout logging and fire in the eastern Brazilian Amazon. Pennsylvania State University, University Park, USA, 2000.

MELICK, D. R.; ASHTON, D. H. The effects of natural disturbances on warm temperate rainforests in south-eastern Australia. AUST. J. Botanic, v. 39, p. 1 - 30, 1991.

NEPSTAD, D. C.; MOREIRA A. G.; ALENCAR, A. A. A. Floresta em chamas: origens, impactos e prevenção de fogo na Amazônia, programa piloto para a proteção das florestas tropicais do Brasil, Brasília, 1999, 172 p.

NUNES, J. R. S.; SOARES, R. V.; BATISTA, A. C. Prometheus - Sistema computacional integrado de controle de incêndios florestais. Floresta, Curitiba. v. 37, p. 369 - 386, 2007. 
RIBEIRO, L. A pressão antrópica e os riscos de incêndios florestais no município de Novo Mundo, Amazônia Mato-grossense, Brasil. 158 p. Tese (Doutorado em Ciências Florestais) - Setor de Ciências Agrárias, Universidade Federa do Paraná, Curitiba, 2009.

RIBEIRO, L.; SOARES, R. V.; BATISTA, A. C. Percepção e uso do fogo por produtores rurais do município de Novo Mundo, Amazônia Mato-grossense In: SIMPÓSIO DE PÓS-GRADUAÇÃO EM CIÊNCIAS FLORESTAIS, 5. 2008, Brasília. Anais...

SENNA, M. C. A.; COSTA, M. H.; PIRES, G. F. Vegetation-atmosphere-soil nutrient feedbacks in the Amazon for different deforestation scenarios. J. Geophys. Res., v. 114, 2009.

SOARES, R. V. Determinação de um índice de perigo de incêndio para a região centro paranaense, Brasil. 72 p. Tese (Doutorado em Engenharia Florestal) - CATIE/IICA, Turrialba, Costa Rica, 1972.

SOARES, R. V. Comparação entre quatro índices na determinação do grau de perigo de incêndios no município de Rio Branco do Sul - PR. Floresta, Curitiba, v. 17, n. 1, 2, p. 31 - 36, 1987.

SOARES, R. V.; BATISTA, A. C. Controle de incêndios florestais: o problema do fogo na floresta e meteorologia aplicada aos incêndios florestais. Brasília, ABEAS, Módulo 2, 120 p, 2002.

SPIEGEL, M. R. Estatística. Ed. McGraw-Hill Brasil Ltda. Cap. 16. 580 p. 1977.

STATGRAPHICS CENTURION XV. 2005. Disponível em: <http://www.statgraphics.com>. Acesso em: 02/02/2009.

WALTER, H.; LIETH, H. Klimadiagramamm-Weltatlos. Jena: Pusl. Gustav Fischer, 1967. 
FLORESTA, Curitiba, PR, v. 41, n. 2, p. 257-270, abr./jun. 2011

Ribeiro, L.; Soares, R. V.; Batista, A. C.; Silva, I. C. 